\title{
Household income modifies the association of insurance and dental visiting
}

\author{
Olga Anikeeva ${ }^{{ }^{*}}$, David S Brennan ${ }^{2}$ and Dana N Teusner ${ }^{2}$
}

\begin{abstract}
Background: Dental insurance and income are positively associated with regular dental visiting. Higher income earners face fewer financial barriers to dental care, while dental insurance provides partial reimbursement. The aim was to explore whether household income has an effect on the relationship between insurance and visiting.

Methods: A random sample of adults aged 30-61 years living in Australia was drawn from the Electoral Roll. Data were collected by mailed survey in 2009-10, including age, sex, dental insurance status and household income.

Results: Responses were collected from $n=1,096$ persons (response rate $=39.1 \%$ ). Dental insurance was positively associated with regular visiting (adjusted prevalence ratio $(P R)=1.18 ; 95 \% \mathrm{Cl}: 1.01-1.36)$. Individuals in the lowest income tertile had a lower prevalence of regular visiting than those in the highest income group (PR $=0.78 ; 95 \% \mathrm{Cl}$ : 0.65-0.93). Visiting for a check-up was less prevalent among lower income earners ( $P R=0.65 ; 95 \%$ Cl: 0.50-0.83). Significant interaction terms indicated that the associations between insurance and visiting varied across income tertiles showing that income modified the effect.
\end{abstract}

Conclusions: Household income modified the relationships between insurance and regular visiting and visiting for a check-up, with dental insurance having a greater impact on visiting among lower income groups.

Keywords: Access, Dental visiting, Income, Insurance

\section{Background}

In Australia, the majority of adults are ineligible to access publicly provided dental care and must pay for dental services, either by making the payments directly or by purchasing dental insurance, which provides partial reimbursement. Public provision of dental care is highly rationed, via waiting lists and triaging systems; therefore, even amongst those who are eligible for publicly funded care, a substantial proportion access care in the private sector $[1,2]$.

Dental insurance has been found to be associated with higher rates of visiting for a check-up and regular dental visiting, [3-11] and was correlated with patient acceptance of prescribed dental treatment, [12] which suggests that insured individuals may face fewer financial barriers to comprehensive dental care. In addition, it has been found that while most individuals obtain basic dental care regardless of their insurance status, dental insurance is

\footnotetext{
* Correspondence: olga.anikeeva@flinders.edu.au

${ }^{1}$ Flinders University Disaster Research Centre, School of Nursing and

Midwifery, Flinders University, Adelaide, SA 5001, Australia

Full list of author information is available at the end of the article
}

associated with use of more expensive dental services, further indicating the capacity of insurance to reduce financial barriers [13].

Income is associated with dental visiting and dental health outcomes, with socioeconomically disadvantaged adults more likely to report a lower frequency of dental visiting, a higher number of missing teeth and poorer self-rated oral health $[1,4,6,7,10,11,14]$. Lower income individuals were found to have higher odds of visiting a dentist for the purpose of pain relief and were more likely to receive extractions than their higher income counterparts [3,4,15-17]. This may reflect the ability of higher income earners to pay for comprehensive dental care, while those with low incomes may delay visiting a dentist until they experience dental problems [4]. Studies have suggested that these associations could not be attributed to personal neglect, such as poor self-care practices or negative attitudes towards dental visiting, among low income individuals [14]. In fact, adults from lower socioeconomic backgrounds were equally inclined to practice dental self-care as their higher socioeconomic

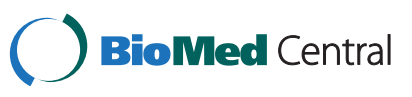


status counterparts. Therefore, distal factors, such as financial barriers to accessing care or long waiting periods for public dental services, may be contributing to the observed associations between income, dental visiting and poor oral health $[14,17]$.

The aim of this study was to investigate whether household income modifies the relationship between dental insurance and dental visiting. While positive associations between dental visiting and insurance have been explored, little Australian research has investigated whether these relationships are consistent across income groups. Understanding variations in associations is important to oral health policy that may be targeted to specific income groups.

\section{Methods}

A random sample of 3000 adults aged 30-61 years living in Australia was drawn from the Electoral Roll by the Australian Electoral Commission. Sample size was determined by using estimates of percentage of persons making a dental visit in the last year (reflecting access to care) and percentage of persons receiving extractions (for comprehensiveness of care). Calculations were made based on comparisons of proportions using an alpha level of 0.05 and a beta of 0.80 . The largest required sample size was $n=336$ per group for comprehensiveness of care, which, allowing for 3 levels of disaggregation, would require a total of 1,008 subjects.

Data were collected by mailed self-complete questionnaires in 2009-2010, with four follow-up mailings to non-respondents at intervals of approximately three to four weeks. Questionnaires collected demographic characteristics, household income, private health insurance details, dental visiting patterns, oral health status and dental behaviours.

\section{Outcome variables}

The outcome variables were regular dental visits (based on the question 'On average how often do you visit a dental professional?') and last visited for a check-up (based on the question 'What was the main reason for your last dental visit?'). The index category for regular visits were those who on average made a dental visit at least once every two years and the index category for reason for visit were those whose last dental visit was for a check-up.

\section{Explanatory variables}

The main explanatory variables were dental insurance status and household income. Dental insurance was coded as insured or uninsured. Household income per year was collected in seven categories (up to $\$ 20,000$, $\$ 20,001$ to $\$ 40,000, \$ 40,001$ to $\$ 60,000, \$ 60,001$ to $\$ 80,000, \$ 80,001$ to $\$ 100,000, \$ 100,001$ to $\$ 120,000$ and more than $\$ 120,000)$ and coded into approximate tertiles.
Other explanatory variables comprised sex, age and tooth brushing. Age was determined by collecting year of birth information from respondents and coded into age groups of 30-39, 40-49 and 50-61 years. Tooth brushing was included as a proxy measure for individual orientation towards personal oral health care and was coded as those who brushed twice a day or more or those who brushed less than twice a day.

\section{Analysis}

Data were analysed using SAS version 9.3. The analyses were restricted to dentate persons. The representativeness of the sample was assessed by comparing a selection of sociodemographic, socioeconomic, dental behaviour and oral health characteristics with population estimates. Unadjusted associations between the dental visiting outcome variables and the main explanatory variables and other variables were examined (Chi-square test, $\mathrm{p}<0.05$ ). In addition, the associations between insurance status and the dental visiting outcome variables, stratified by household income, were calculated. Prevalence ratios adjusted for explanatory variables were estimated by log binomial models. Significant results were based on $95 \%$ confidence intervals. Interaction terms were fit for household income by insurance to assess whether the relationship between visiting and insurance was modified by income.

The research was approved by the Human Research Ethics Committee of the University of Adelaide and participants gave informed consent prior to participation in the study.

\section{Results}

\section{Response and sample characteristics}

Responses were collected from $\mathrm{n}=1,096$ persons (response rate $=39.1 \%)$. Of these, $4 \%(n=44)$ were edentulous or of unknown dentate status and were excluded from analyses. Thus, responses from $\mathrm{n}=1,052$ individuals were analysed in this study. The respondents showed a similar profile to comparable population survey data in terms of number of teeth, lower dentures, making a dental visit in the last 12 months, place of birth and education level (Table 1). However, a lower percentage of the study participants, compared to population estimates, were males, younger (aged 30-39 years), in the higher $(>\$ 100,000)$ income category, had dental insurance, or visited for a check-up at their last visit. Study participants also tended to have a higher percentage with upper dentures and more likely to speak English at home.

\section{Effect of household income on the relationship between dental insurance and dental visiting}

The study population distributions and dental visiting by sex, age, household income, tooth brushing and insurance status are presented in Table 2. Overall, $71.5 \%$ made 
Table 1 Distribution of explanatory variables and comparison of dentate study participants with the population profile

\begin{tabular}{|c|c|c|c|c|c|}
\hline \multirow[b]{2}{*}{ Oral health status } & \multirow[t]{2}{*}{${ }^{\dagger}$ Census data } & \multicolumn{2}{|c|}{${ }^{\text {F}}$ Population survey data } & \multicolumn{2}{|c|}{ Study participants } \\
\hline & & $\%$ & $(95 \% \mathrm{Cl})$ & $\%$ & $(95 \% \mathrm{Cl})$ \\
\hline Number of teeth - mean & - & 25.2 & $(24.8,25.6)$ & 26.5 & $(26.1,26.8)$ \\
\hline Denture (upper jaw) & - & 7.8 & $(6.8,8.9)$ & 11.7 & $(9.8,13.8)$ \\
\hline Denture (lower jaw) & - & 2.1 & $(1.6,2.7)$ & 3.9 & $(2.8,5.3)$ \\
\hline \multicolumn{6}{|l|}{ Dental behaviour } \\
\hline Last dental visit $<12$ months & - & 60.5 & $(58.3,62.6)$ & 59.7 & $(56.7,62.7)$ \\
\hline Check-up at last dental visit & - & 57.2 & $(54.9,59.5)$ & 50.4 & $(47.4,53.5)$ \\
\hline Dental insurance & - & 60.0 & $(57.9,62.1)$ & 53.9 & $(51.0,57.0)$ \\
\hline \multicolumn{6}{|l|}{ Socio-demographics } \\
\hline Male sex & 49.2 & 49.8 & $(47.6,51.9)$ & 42.3 & $(39.3,45.4)$ \\
\hline Age $30-39$ years & 34.4 & 34.1 & $(31.9,36.4)$ & 24.7 & $(22.1,27.4)$ \\
\hline Age $40-49$ years & 35.0 & 33.0 & $(31.1,35.0)$ & 32.9 & $(30.0,35.8)$ \\
\hline Age $50-61$ years & 30.6 & 32.9 & $(31.1,34.8)$ & 42.5 & $(39.4,45.5)$ \\
\hline Australian born & - & 79.6 & $(77.8,81.3)$ & 80.7 & $(78.2,83.1)$ \\
\hline English main language at home & - & 88.2 & $(86.6,89.7)$ & 94.6 & $(93.1,95.9)$ \\
\hline Education level of diploma or degree & - & 44.6 & $(42.5,46.8)$ & 44.6 & $(41.5,47.7)$ \\
\hline \multicolumn{6}{|l|}{ Socio-economic status } \\
\hline Household income $<\$ 60,000$ & - & 24.2 & $(22.2,26.2)$ & 35.2 & $(32.2,38.2)$ \\
\hline Household income $>\$ 60,000-100,000$ & - & 37.2 & $(35.1,39.3)$ & 32.2 & $(29.3,35.1)$ \\
\hline Household income $>\$ 100,000$ & - & 38.7 & $(36.5,40.9)$ & 32.6 & $(29.7,35.6)$ \\
\hline
\end{tabular}

+Census 2006: Australia, 30-59 year-olds [26].

‡National Dental Telephone Interview Survey 2010: Australia, dentate 30-61 year-olds.

regular dental visits and 50.4\% last visited for a check-up. With the exception of one explanatory variable, sex, regular visits and visiting for a check-up were associated with all explanatory variables. Sex was associated with visiting for a check-up but was not associated with regular visiting (Table 2).

Overall, 53.9\% of dentate adults were insured (Table 2). Proportion insured varied by household income with those in the lowest income group (33.5\%) less likely to be insured than those in the $\$ 60,001$ to $\$ 100,000$ group (61.3\%) and the highest income group (70.4\%).

The stratified bivariate associations are presented in Figures 1 and 2. The association between dental insurance and dental visiting varied across household income groups. Among those in the highest income group the proportion making regular visits and the proportion who visited for a check-up did not vary by insurance status. In contrast, for those in the lowest income group, the proportion making regular visits and visiting for a check-up was lower for uninsured adults than those who were insured, although differences in the proportion making regular visits was not significant (95\% CIs overlapped) (Figure 1 and Figure 2).

After adjusting for explanatory variables the significant positive association between insurance status and regular dental visiting persisted. Insured individuals had a higher prevalence of visiting at least once every two years compared to participants without insurance (adjusted PR = 1.18; 95\% CI: 1.01-1.36). Household income also remained positively associated with regular dental visiting, with participants in the lowest income group having a lower prevalence of regular dental visiting (adjusted $\mathrm{PR}=0.78$; 95\% CI: 0.65-0.93) compared to those in the highest income group. Furthermore, the interaction between insurance and household income group, indicated in Figure 1, also persisted after controlling for other explanatory variables. The prevalence ratio of regular visiting was higher for insured adults in the lowest income group compared to insured in the highest income group (Table 2).

In terms of visiting a dentist for the purpose of a check-up, insurance status was not significantly associated (adjusted PR $=1.13$; 95\% CI: 0.92-1.39); however, household income was positively associated. Participants in the lowest income category had a significantly lower prevalence of last visiting for a check-up (adjusted $\mathrm{PR}=0.65$; 95\% CI: 0.50-0.83) compared to those in the highest income group. Consistent with the pattern observed for regular visiting, there was a significant interaction between insurance status and household income, indicating that the associations between insurance and visiting for a check-up significantly vary by household income group (Table 2). 
Table 2 Distributions and dental visiting by sex, age, income, tooth brushing, and insurance

\begin{tabular}{lllllll}
\hline Distributions & $\begin{array}{l}\text { Regular dental } \\
\text { visits }^{\dagger}\end{array}$ & $\begin{array}{l}\text { Check-up } \\
\text { visits }\end{array}$ & $\begin{array}{l}\text { Adjusted effects: } \\
\text { regular dental visits }\end{array}$ & $\begin{array}{l}\text { Adjusted effects: } \\
\text { check-up visits }\end{array}$ \\
\hline$\%$ & $\%$ & $P$ P value & $\% \quad P$ value & $P R(95 \%$ Cl) $P$ value & $P R(95 \%$ Cl) $P$ value
\end{tabular}

Sex

Male

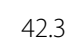

57.7

$$
24.7
$$

50-61 yrs

Household income

Up to $\$ 60,000$

$\$ 60,001-100,00$

$>\$ 100,000$

\section{Tooth brushing}

Twice a day or more Less than twice a day

$\begin{array}{ll}35.2 & 62.9 \\ 32.2 & 73.9 \\ 32.6 & 78.6\end{array}$

$<0.0001$

** 41

73.9

78.6

67.6

0.0473

57.0
49.3

49.3

0.0486

* Ref.

$1.06(0.96,1.16) \quad 0.2607$

$1.11(1.02,1.21) \quad 0.0154$

47.6

57.5

78.7

62.2

$<0.0001$

** 57.0

41.7

$<0.0001$

* 0.78

52.0

60.4

$0.85(0.70,1.04) \quad 0.1154$

Ref.

NS $0.89(0.78,1.01) \quad 0.0688$ NS

Dental insurance

Insured

Uninsured

46.1

83.2

57.7

$<0.0001$

* $\quad 60.8<0.000$

38.3

0.0001

* 1.

Ref.

Ref.

Interaction

Up to $\$ 60,000 \times$ Insured

$\$ 60,001-100,00 \times$ Insured -

Notes.

Chi-Square statistic, $*(P<0.05), * *(P<0.01)$.

PR: Prevalence Ratio.

t: On average visit a dental practitioner at least once every two years.

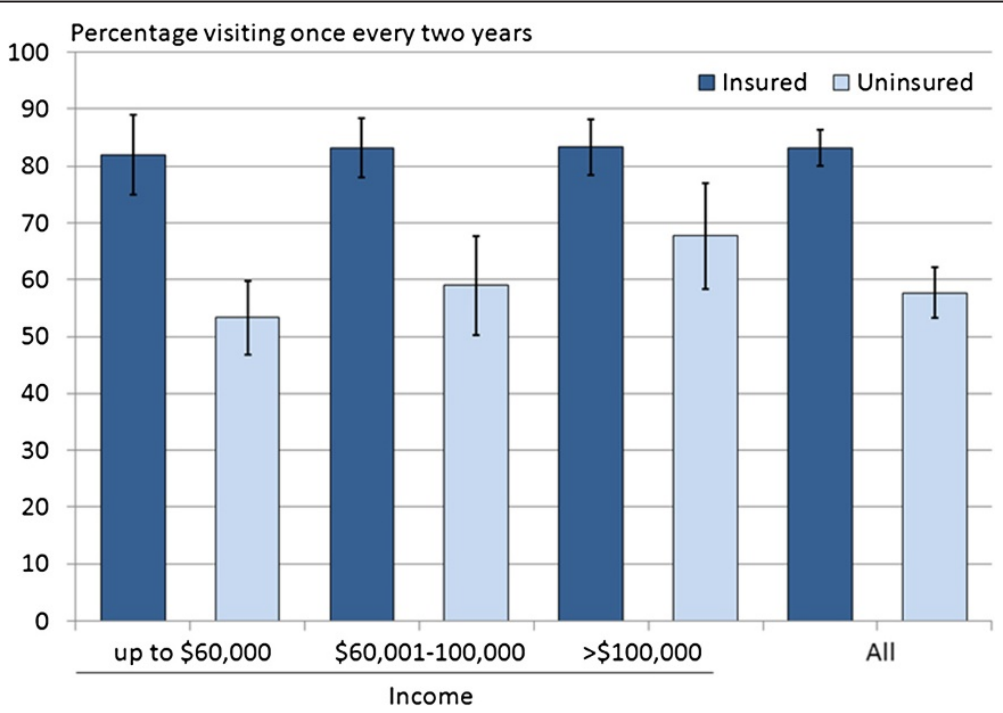

Figure 1 Regular dental visiting by insurance status and household income with $95 \%$ confidence intervals. 


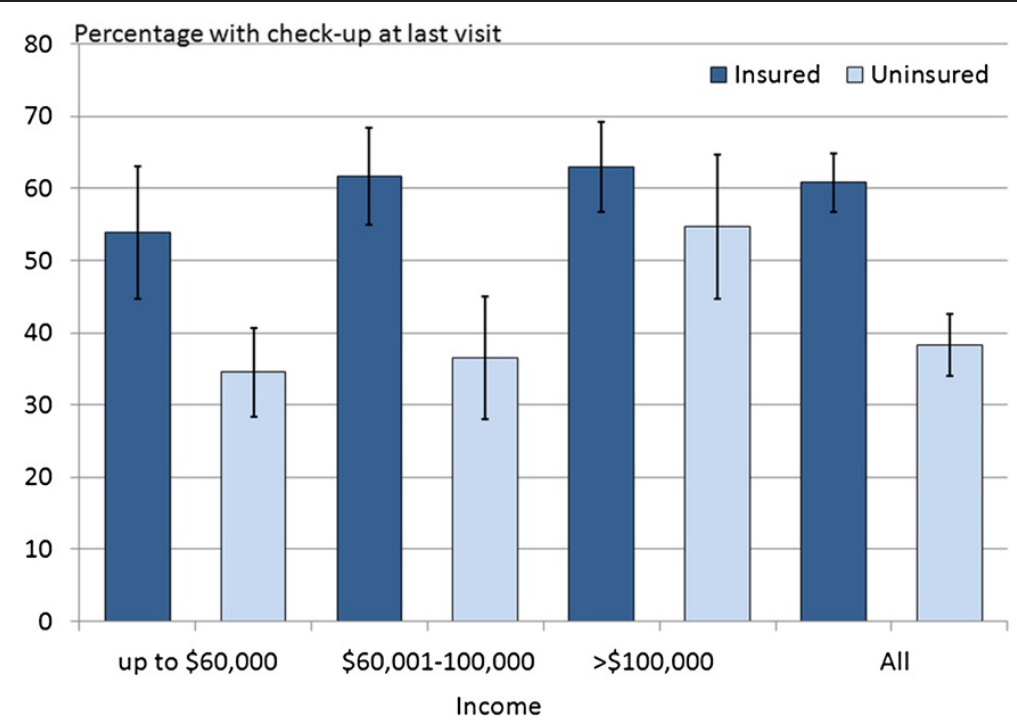

Figure 2 Visiting for a check-up by insurance status and household income with $95 \%$ confidence intervals.

\section{Discussion}

The key finding of this study was that household income modified the relationship between dental insurance and regular dental visiting and visiting for a check-up, with insurance status having a greater impact on visiting among lower income households.

The results of previous studies were consistent with the finding that household income is positively associated with regular visiting and visiting for a check-up $[4,7,10,11,14]$. Individuals from lower socioeconomic backgrounds were likely to lack the necessary economic resources to obtain regular preventive dental care [14]. Low income adults attending for care in public dental clinics often face long waiting periods, [18] and are more likely to receive emergency care rather than preventive care such as check-ups [16]. Similarly, adults from low income households were more likely to report that the cost of dental care prevented them from obtaining recommended treatment, such as regular check-ups [2,4]. Financial barriers also had an impact on the likelihood of regular dental visiting, with lower income individuals more likely to avoid or delay visiting a dentist until symptoms or problems arose $[4,14,15]$.

The finding that dental insurance was positively associated with regular dental visiting was consistent with earlier findings [3-5,7-10]. This trend can be explained by the partial removal of financial barriers provided by dental insurance. Insured individuals were more likely to obtain recommended regular dental care than their uninsured counterparts, who may have avoided or delayed visiting a dentist until problems or symptoms appeared [4].

In this study household income was found to modify the association between insurance status and dental visiting. Specifically, dental insurance was associated with visiting behaviour to a greater extent among lower income groups.
The higher percentage of regular dental visits and checkup visits observed for insured persons in the unadjusted analysis was less pronounced in the higher income group, but was more apparent in lower and middle income groups. Adjusted for other explanatory variables these associations remained significant. This suggests that dental insurance may be a more important enabling factor for access to dental care among lower income groups compared to higher income groups. This finding is consistent with a Canadian study which found that dental insurance was an important contributing factor to increased utilisation of dental services, and that this effect was most pronounced among lower income households [19,20]. Although adults from higher income households were found to be more likely to purchase dental insurance, $[1,3,4,6,20]$ they derived fewer financial benefits from insurance compared to their lower income counterparts.

While over one-fifth of insured adults in Australia report financial barriers to receiving dental care, [21] which may in part be explained by the limited cost attenuation and relatively low annual claim limits provided by Australian dental insurance plans [9,22], nevertheless the persistent associations between having insurance and dental visiting after controlling for confounders supports the conclusion that dental insurance is an important enabling factor in dental visiting. These findings indicate that increasing coverage of dental insurance may improve access to care for lower income groups, but may have less influence on visiting patterns of higher income groups.

\section{Limitations}

A limitation of this study was that household income does not take into account the number of people dependent on that income. However, clear gradients in dental visiting 
were observed across household income groups. While the response yield provided sufficient numbers for analysis, the response rate was low, particularly with multiple follow-ups [23]. The electoral roll should provide an adequate sampling frame for a population survey of adults. While a response rate of $60 \%$ may be considered adequate as a benchmark, [24] response rates require evidence to examine bias [25]. Key demographic characteristics of sex and age from the 2006 Census showed the study participants were less likely to be male and from the younger adult age group [26]. Other comparable population sample data also showed the survey respondents were more likely to be from the lower income group, and have lower levels of dental insurance and check-ups at the last dental visit. The cross-sectional nature of the analysis limits the ability to comment on the observed associations in terms of causal relationships.

While prevalence ratios of visiting may appear relatively low (Table 2), seemingly marginal PRs in relation to dental visiting can have a substantial impact on aggregate demand for dental visits. For example, ignoring the role of other unmeasured confounders, an 18\% higher probability of regular visiting by insured adults would indicate that if uninsured Australian adults were to become insured, the resulting increase in demand for dental visits would be in excess of 1.8 million dental visits per annum (based on a uninsured population of 11.5 million people and 1.5 visits per capita).

\section{Conclusions}

Although the results of this study should be interpreted with caution due to the aforementioned limitations, the findings showed that household income modified the relationships between insurance and regular visiting and visiting for a check-up. Dental insurance was found to have a greater effect on visiting among lower income groups. This finding has implications for oral health policy, suggesting that lower socioeconomic groups may derive greater benefit from dental insurance than their higher income counterparts.

\section{Competing interests}

The authors declare that they have no competing interests.

\section{Authors' contributions}

All authors were involved in the analysis and interpretation of data, revising the paper and giving final approval for publication of the manuscript. OA prepared the draft manuscript, DB was involved in design of the project, and DT in acquisition and preparation of data. All authors read and approved the final manuscript.

\section{Acknowledgements}

The research was supported by a project grant (565321) and Career Development Award from the National Health and Medical Research Council (627037) and a CRE (1031310). The researchers would like to acknowledge the contributions of the participants and research assistants David Harley and Beverly Ellis. The contents are solely the responsibility of the administering institution and authors and do not reflect the views of NHMRC.

\section{Author details}

${ }^{1}$ Flinders University Disaster Research Centre, School of Nursing and Midwifery, Flinders University, Adelaide, SA 5001, Australia. ${ }^{2}$ Australian Research Centre for Population Oral Health (ARCPOH), School of Dentistry, The University of Adelaide, Adelaide, SA 5005, Australia.

Received: 18 March 2013 Accepted: 9 October 2013

Published: 23 October 2013

\section{References}

1. FitzGerald EM, Cunich M, Clarke PM: Changes in inequalities of access to dental care in Australia 1977-2005. Aust Econ Rev 2011, 44(2):153-166.

2. Spencer AJ, Harford JE: Dental Care. In Australia's Dental Generations: the National Survey of Adult Oral Health 2004-06 AlHW cat no DEN 165. Edited by Slade GD, Spencer AJ, Roberts-Thomson KF. Canberra: Australian Institute of Health and Welfare; 2007:143-172.

3. Brennan DS, Spencer AJ: Influence of patient, visit, and oral health factors on dental service provision. J Public Health Dent 2002, 62(3):148-157.

4. Australian Research Centre for Population Oral Health: Oral health and access to dental care in Australia - Comparisons by cardholder status and geographic region. Aust Dent J 2005, 50:4282-4285.

5. Australian Research Centre for Population Oral Health: Factors associated with infrequent dental attendance in the Australian population. Aust Dent J 2008, 53:358-362.

6. Kaylor MB, Polivka BJ, Chaudry R, Salsberry P, Wee AG: Dental insurance and dental services use by U.S. women of childbearing age. Public Health Nurs 2011, 28(3):213-222.

7. Newman JF, Gift HC: Regular pattern of preventive dental services - a measure of access. Soc Sci Med 1992, 35(8):997-1001.

8. Brennan DS, Spencer AJ, Szuster FSP: Insurance status and provision of dental services in Australian private general practice. Community Dent Oral Epidemiol 1997, 25:423-428.

9. Teusner DN, Brennan DS, Spencer AJ: Dental insurance, attitudes to dental care, and dental visiting. J Public Health Dent 2013, 73(2):103-111.

10. Bhatti T, Rana Z, Grootendorst P: Dental insurance, income and the use of dental care in Canada. J Can Dent Assoc 2007, 73(1):57.

11. Brennan DS, Ellershaw AC: Insurance and use of Dental Services: National Dental Telephone Interview Survey 2010. Dental Statistics and Research Series no. 62. Cat. no. DEN 219. Canberra: AlHW; 2012.

12. Stafford WL, Edenfield SM, Coulton KM, Beiter T: Insurance as a predictor of dental treatment: a pilot study in the Savannah, Chatham County area. J Dent Hyg 2010, 84(1):16-23.

13. Bendall $D$, Asubonteng $P$ : The effect of dental insurance on the demand for dental services in the USA: a review. J Manag Med 1995, 9(6):55-68.

14. Sanders AE, Spencer AJ, Slade GD: Evaluating the role of dental behaviour in oral health inequalities. Community Dent Oral Epidemiol 2006, 34:71-79.

15. Roberts-Thomson KF, Luzzi L, Brennan DS: Social inequality in use of dental services: relief of pain and extractions. Aust $N Z J$ J Public Health 2008, 32(5):444-449.

16. Brennan DS, Do LG, Slade GD: Caries experience of adults attending private and public dental clinics in Australia. J Public Health Dent 2011 71:32-37.

17. Brennan DS, Luzzi L, Roberts-Thomson KF: Dental service patterns among private and public adult patients in Australia. BMC Health Serv Res 2008, 8:1.

18. Australian Health Ministers' Advisory Council: Oral Health of Australians. National Planning for Oral Health Improvements. Adelaide: SA Department of Human Services; 2001.

19. Millar WJ, Locker D: Dental insurance and use of dental services. Health Rep 1999, 11:55-67.

20. Locker D, Maggirias J, Quinonez C: Income, dental insurance coverage, and financial barriers to dental care among Canadian adults. J Public Health Dent 2011, 71:327-334.

21. Harford JE, Ellershaw AC, Spencer AJ: Trends in access to dental care among Australian adults 1994-2008. In Dental Statistics and Research Unit Series no 55 Cat no DEN 204. Canberra: Australian Institute of Health and Welfare; 2011 
22. Private Health Insurance Ombudsman (PHIO) Australian Government: The State of the Health Funds Report 2008. Report Required by 238 5(c) of the Private Health Insurance Act 2007. Australia, Co; 2009.

23. Dillman DA: Mail and Telephone Surveys. The Total Design Method. New York: Wiley; 1978.

24. Mangione TW: Mail Surveys. Improving the Quality. CA: Sage; 1995.

25. Lee S, Brown ER, Grant D, Belin TR, Brick JM: Explaining nonresponse bias in a health survey using neighbourhood characteristics. Am J Public Health 2009, 99(10):1811-1817.

26. 2006 Census of Population and Housing. Australia by Sex Male/Female (SEXP) and Age 5 Year Age Groups (AGEP). Counting: Persons, Place of Usual Residence. www.censusdata.abs.gov.au/CDATAOnline/prenav/.

doi:10.1186/1472-6963-13-432

Cite this article as: Anikeeva et al: Household income modifies the association of insurance and dental visiting. BMC Health Services Research 2013 13:432.

\section{Submit your next manuscript to BioMed Central and take full advantage of:}

- Convenient online submission

- Thorough peer review

- No space constraints or color figure charges

- Immediate publication on acceptance

- Inclusion in PubMed, CAS, Scopus and Google Scholar

- Research which is freely available for redistribution 